\title{
Potential and performance of a polydopamine-coated multiwalled carbon nanotube/polysulfone nanocomposite membrane for ultrafiltration application
}

Merry Sianipar ${ }^{1}$, Seung Hyun Kim ${ }^{1 *}$, Choongsik Min ${ }^{1}$, Leonard D. Tijing ${ }^{2}$, Ho Kyong Shon ${ }^{2}$

${ }^{1}$ Faculty of Civil Engineering, Kyungnam University, 449 Woryeong-dong, Masanhappo-gu, Changwon-si, Gyeongsangnam-do, Republic of Korea

${ }^{2}$ Centre for Technology in Water and Wastewater, School of Civil and Environmental Engineering, University of Technology, Sydney (UTS), P.O. Box 123, 15 Broadway, NSW 2007, Australia.

*Corresponding author: tel.: +82 55249 2665; fax: +82 55249 2664; Email address: shkim@kyungnam.ac.kr (S.H. Kim)

\begin{abstract}
The addition of multiwalled carbon nanotubes (MWNTs) as inorganic fillers is well known to improve membrane performance for water desalination. Most MWNTs are treated by acid treatment to enhance their hydrophilicity before their applications in membranes. However, acid treatment leads to structural damages of the MWNT wall. An alternative way of improving the hydrophilicity of MWNTs is through coating of polydopamine (Pdop), where MWNT wall damage is avoided. In the present study, polydopamine-coating on MWNT is carried out at $\mathrm{pH} 8.5$ and at room temperature $\left(23-25^{\circ} \mathrm{C}\right)$. Different concentrations (0.1 to 0.5 wt\%) of Pdop-MWNTs were incorporated into polysulfone (Psf) membranes fabricated by phase inversion. The results showed that the incorporation of Pdop-coated MWNTs has increased the membrane permeability using BSA solution (1,000 ppm) by 19 to 50\% depending on the amount of Pdop-MWNTs in the membrane, and has maintained good rejection performances (99.88\%). Moreover, the antifouling properties of the nanocomposite membranes were also improved. Here, the optimum dose was determined to be $0.1 \mathrm{wt} \%$ of Pdop-MWNTs. Furthermore, even though the Pdop-MWNT/Psf membranes showed lower permeability than acid-MWNT/Psf membrane, the Pdop-MWNT/Psf membrane obtained higher mechanical strength and would be potentially sustainable for a long term ultrafiltration operation.
\end{abstract}


Keywords: Polydopamine; Multiwalled carbon nanotube; Hydrophilic; Fouling; Ultrafiltration

\section{Abbreviation}

BSA $\quad$ Bovine serum albumin

CA Contact angle

CNT Carbon nanotube

DI Deionized water

FTIR Fourier-transform infrared spectroscopy

$\mathrm{H}_{2} \mathrm{SO}_{4} \quad$ Sulfuric acid

HCl Hydrochloric acid

$\mathrm{HNO}_{3} \quad$ Nitric acid

MWCO Molecular weight cut-off

MWNT Multiwalled carbon nanotube

NMP N-methyl-2-pyrrolidone

Pdop Polydopamine

PEG Polyethylene glycol

PEO Poly(ethylene oxide)

Psf Polysulfone

PVP Polyvinylpyrrolidone

RO Reverse osmosis

SEM Scanning electron microscopy

TEM Transmission electron microscopy

TOC Total organic carbon

UF Ultrafiltration

UV/vis Ultraviolet/visible light 


\section{Nomenclature}

$\begin{array}{ll}A & \text { Membrane surface area }\left(\mathrm{m}^{2}\right) \\ C_{f} & \text { Feed concentration (g/L) } \\ C_{p} & \text { Permeate concentration (g/L) } \\ \text { FRR } & \text { Flux recovery ratio (\%) } \\ h & \text { Membrane thickness (cm) } \\ J_{f} & \text { Membrane flux using BSA solution }\left(\mathrm{kg} / \mathrm{m}^{2} \mathrm{~h}\right) \\ J_{w c} & \text { Membrane flux of the cleaned membrane }\left(\mathrm{kg} / \mathrm{m}^{2} \mathrm{~h}\right) \\ J_{w v} & \text { Membrane flux using deionized water }\left(\mathrm{kg} / \mathrm{m}^{2} \mathrm{~h}\right) \\ m & \text { weight of permeate water (g) } \\ P & \text { Membrane porosity (\%) } \\ R_{i r} & \text { Irreversible fouling ratio (\%) } \\ R_{r} & \text { Reversible fouling ratio (\%) } \\ R_{t} & \text { Total flux loss (\%) } \\ W_{d} & \text { Dry weight of membrane (g) } \\ W_{w} & \left.\text { Wensity (g/cm }{ }^{3}\right) \\ R_{t} & \end{array}$

\section{Introduction}

The use of membranes has become popular over the years for water and wastewater treatment processes [1]. However, the common problem occurring in membrane application is the trade-off between permeability and selectivity of the membranes [2,3]. Furthermore, the high expenses for flushing the membrane as a consequence of the fouling tendency [4] have made people reconsider the efficiency of implementing membrane filtration. Continuous research efforts are carried out to improve the membrane separation and regeneration efficiency by optimizing process parameters or by developing new membranes. In the past few decades, the advent of nanotechnology has sparked many developments in materials science 
and engineering, including the manufacture of new membranes and materials for separation technologies. Among the nanomaterials, CNTs [5] have gained interest as the main material or as filler material of polymer composites for water and wastewater treatment. CNTs possess many unique properties such as high aspect ratio, small size, very low density, high tensile strength (reportedly more than 100 times that of stainless steel), and excellent thermal and electrical properties [6,7]. Many review papers have been reported in literature on the use of CNTs for desalination, removal of contaminants in drinking water, and other water treatment applications $[8,9,10]$.

The role of MWNTs as inorganic fillers in the membrane is predicted to enhance the membrane performance [11]. However, their hydrophobicity and inert characteristics create dispersibility problems in many kinds of solvents. Thus, to solve the dispersion problem, several approaches for producing hydrophilic MWNTs in the membrane fields have been developed [12]. Two main approaches are usually carried out to disperse the MWNTs: mechanical process and chemical modification. Mechanical process involves the use of high shearing force through sonication with or without ball-milling or grinding of MWNTs. Chemical modification on the other hand usually involves acid treatment or the use of surfactants to modify the surface properties of MWNTs. The chemical modification approach followed by sonication is usually carried out by most researchers to disperse MWNTs. Surface modification of MWNTs could provide a pathway to the effective mixing of MWNTs in solution or hybrid assemblies [13]. Interestingly, the enhancement in the hydrophilicity of MWNTs is found to improve not only their dispersion ability but also has a positive impact on the membrane performance [14,15]. For example, Phao et al. [16] improved the dispersbility and wettability of CNTs by doping the CNTs with nitrogen (N-CNTs). NCNTs/polyethersulfone membranes were then fabricated by modified phase inversion process, and the permeability tests showed up to $70 \%$ increase in water flux with the use of polyethersulfone membranes incorporated with N-CNTs.

One of the well-known functionalization techniques is through acid treatment of MWNTs. Nitric and sulfuric acid or a combination of both are usually utilized for acid treatment since it is easy to implement in the laboratory and industrial settings [17]. The acid treatment leads to oxidation of the MWNT walls, wherein the introduction of the oxygencontaining groups such as carboxyl, carbonyl, and phenol groups increases the hydrophilicity of the MWNTs [18]. However, this acid treatment is prone to breakage of the MWNT wall structure [19]. Additionally, the structural integrity of nanocomposite could be decreased due 
to the presence of carboxylic groups on the MWNT surface [20]. Moreover, the use of aggressive acids could have potential impact to the surroundings during the chemical modification process and its disposal. Thus, it is desired to find alternative approaches for improving the hydrophilicity and dispersibility of MWNTs.

One of the recent advances is the use of Pdop coating on materials for improving their wettability [21]. Pdop, a biorepeated polymer of dopamine monomer, has amine and hydroxyl groups [22,23], which can increase the hydrophilicity of the coated material $[24,25]$. Reports indicated improved membrane performances such as permeability and antifouling properties after the addition of a Pdop film on the membranes [26,27,28]. Karkhanechi et al. [29] modified a RO membrane with Pdop and found an improved anti-fouling property of the composite membrane, which was mainly attributed to the bactericidal property of the protonated amine groups of Pdop. Furthermore, Pdop which has similar properties with the adhesive secretion of mussel is reported to increase the mechanical strength of the coated materials [30]. Huang et al. [31] investigated the coating effect of Pdop on the mechanical properties and wettability of electrospun nanofibers. They reported an increase of 100 to 300\% in tensile strength and Young's modulus without sacrificing the flexibility of the membrane as Pdop promotes bonding of the nodes of the fibers. Furthermore, an increase in hydrophilicity was observed for the hydrophobic Psf nanofibers. Considering its hydrophilic characteristic and high mechanical strength, Pdop shows a potential as a coating material to MWNTs to improve their hydrophilicity without damaging the wall structures of the MWNTs and at the same time enhancing the strength of the MWNT structure. A recent study reported an enhanced separation performance and anti-fouling capability of Psf membrane when incorporated with Pdop/CNTs for forward osmosis application [32].

In this study, MWNTs were coated with Pdop to improve their dispersibility and to provide an antifouling behavior. First, the optimal Pdop coating time on MWNTs was investigated. Pdop-MWNTs were then used as fillers for Psf membranes and their permeability and antifouling properties were investigated for ultrafiltration application. The permeability and mechanical strength of Pdop-MWNT/Psf membranes were also compared to those of acidMWNT/Psf membranes for their ultrafiltration performance.

\section{Materials and Methods}

\subsection{Materials}


Pristine MWNTs (HANOS CM 95) with a length of 10-50 nm, and outer and inner of diameters $\pm 10 \mathrm{~nm}$ and $\pm 4 \mathrm{~nm}$, respectively, were purchased from Hanwha Nanotech Company, Republic of Korea. Polysulfone (Udel P-3500 LCD, 75-81 kg/mol) as a polymer matrix was bought from Solvay, Belgium. Dopamine hydrochloride $\left(\mathrm{C}_{8} \mathrm{H}_{11} \mathrm{NO}_{2} . \mathrm{HCl}, 189.6 \mathrm{~g} / \mathrm{mol}\right)$, Tris$\mathrm{C}_{4} \mathrm{H}_{11} \mathrm{NO}_{3}, 121.14 \mathrm{~g} / \mathrm{mol}$, poly(ethylene oxide) (PEO, $100 \mathrm{kDa}$ ), PVP (55 kDa), PEG (35 kDa), and BSA (67 kDa) were provided by Sigma Aldrich, USA. Various solutions such as NMP, $\mathrm{HNO}_{3}$, and $\mathrm{H}_{2} \mathrm{SO}_{4}$ were received from Daejung (Republic of Korea). For membrane filtration,

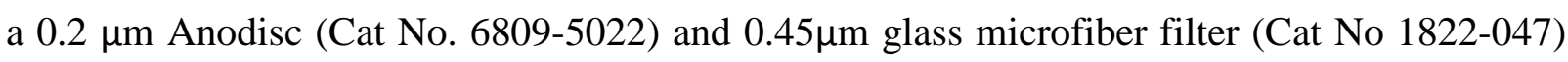
was used, which was purchased from Whatman GmbH Dassel, Germany (Whatmann International Ltd). DI water was produced from Ultra Water Purification System (Ultra 370 Series aqua max Younglin Company, Republic of Korea).

\subsection{MWNT functionalization}

\subsubsection{Polydopamine coating of MWNT}

In brief, $15 \mathrm{mM}$ of Tris was added to $200 \mathrm{mg}$ of dopamine- $\mathrm{HCl}$ solution in $100 \mathrm{ml}$ of DI water (2 g/L) [33]. The mixture was left in ambient air for 1 min to produce polydopamine. The color of the mixture became darker indicating the oxidation of dopamine (i.e. selfpolymerization) and it started to change to polydopamine [34]. Then, $100 \mathrm{mg}$ of pristine MWNTs was added and stirred in a stirrer cell (Model HS15-26P, Misung Company, Republic of Korea) to let the coating process occur (room temperature: $23-25^{\circ} \mathrm{C}$ ) [30,34]. It was assumed that continuing oxidation still occurred during the coating process. The $\mathrm{pH}$ of the solution was set at 8.5. The polydopamine properties generated at $\mathrm{pH} 8.5$ showed negative charge characteristics $[35,36]$.

After preliminary test to find the optimum coating time between 6, 16, and $36 \mathrm{~h}$, it was observed that $16 \mathrm{~h}$ duration produced the best result. After coating, the mixture was centrifuged (High Speed Refrigerated Centrifuge, Model SUPRA 22K, H951106, Hanil Company, Republic of Korea) and filtered (0.2 $\mu$ m Anodisc 47 filter). Pdop-coated-MWNTs (or simply referred herein after as Pdop-MWNTs) were dried in a vacuum oven at $60^{\circ} \mathrm{C}$ overnight.

\subsubsection{Acid functionalization of MWNT}

For comparison, the MWNTs were also functionalized by acid treatment. MWNTs were acid-treated in a mixture of $\mathrm{HNO}_{3}$ and $\mathrm{H}_{2} \mathrm{SO}_{4}(1: 3 \mathrm{v} / \mathrm{v})$ before being washed by DI and left to dry at room temperature overnight. The dried MWNTs were then ultrasonicated in 1:3 (v/v) 
$\mathrm{HNO}_{3}: \mathrm{H}_{2} \mathrm{SO}_{4}$ mixture at $80^{\circ} \mathrm{C}$ for $1 \mathrm{~h}$ [37]. Finally, the MWNTs were washed and filtered using a $0.45 \mu \mathrm{m}$ glass microfiber filter until the $\mathrm{pH}$ value of the MWNT solution reached to $\mathrm{pH}$ 7 and again dried in a vacuum oven at $60^{\circ} \mathrm{C}$ overnight. Furthermore, acid treated MWNT was applied in a Psf membrane and the performance (permeability) was investigated.

\subsection{Fabrication of composite membranes}

The neat Psf and composite membranes were fabricated using a phase inversion method [37] with different MWNT loadings as listed in Table 1. NMP was chosen as the solvent due to its strong interaction with polymer and based on our preliminary studies, NMP was the optimal solvent to effectively disperse MWNTs in our present study. Pdop- or acid-treated MWNTs in NMP solvent were mixed for a minimum of $7 \mathrm{~h}$ using a tip sonicator (Powersonic type 520, 700 W, Hwashin Technology Company, Republic of Korea). Then, a certain amount of Psf was added and stirred at room temperature until complete dissolution of Psf in the solution. The MWNT/Psf solutions were then sonicated for another $3 \mathrm{~h}$ to remove air bubbles, and left standing alone at room temperature overnight to reach ambient temperature. To produce the membrane, the casting solutions (i.e., MWNT/Psf blends) were casted with 100 $\mu \mathrm{m}$ thickness of the casting knife on a polyester non-woven fabric surface. Then, the formed membranes were immersed into a coagulation bath using water as non-solvent for 10 min. After which, the membrane was taken out from the water and subsequently rinsed with and stored in DI water.

\subsection{Characterization and measurements}

The morphology and structure of the functionalized MWNTs and the membranes were characterized by SEM (Hitachi S-4200, Japan) and TEM (JEM 2100, JEOC, Japan). Chemical analyses of the samples were carried out by FTIR (FTIR-460 plus Jasco, Japan) and Raman spectroscopy (JP/NRS-3300 Jasco, Japan). The dispersion ability of the functionalized MWNTs was characterized by UV-vis light spectrocopy (Optizen POP QX5w4407-109038-00, Republic of Korea). The wettability of the membranes was characterized by contact angle (CA) measurement utilizing the sessile drop method using a contact angle meter (Phoenix 300, SEO, Republic of Korea). The mechanical properties of the membrane were measured using a universal testing machine (BESTUTM-00005MD). The viscosity of the casting solutions was determined using Brookfield viscometer (LVDV-11+P, USA). The porosity of the membranes was obtained using the following equation [38]: 
$P(\%)=\frac{W_{w}-W_{d}}{A \times h \times \rho_{w l}} \times 100 \%$

where $P$ is the membrane porosity, $A$ is the membrane surface area $\left(\mathrm{cm}^{2}\right), \mathrm{h}$ is the membrane thickness $(\mathrm{cm}), \rho_{w l}$ is the density $\left(\mathrm{g} / \mathrm{cm}^{3}\right)$ of the wetting liquid, i.e., ethanol) and $W_{w}$ and $W_{d}$ are the wet and dry weights of the membranes (g), respectively. In order to obtain the dry weights of membranes, the wet membranes were dried in a vacuum oven at $60^{\circ} \mathrm{C}$ for one night. On the other hand, MWCO was calculated based on the previous method from literature [39] using PEO, PEG, and PVP solution as feed water in the rejection performance.

There were two configurations of filtration tests used in this study: cross flow (see Figure 1a) and dead-end (see Figure 1b) filtration. The cross-flow filtration system was operated by using a membrane with an effective membrane area of $20.4 \mathrm{~cm}^{2}$. The permeation test was conducted at 4 bar for $3 \mathrm{~h}$ at room temperature $\left(23-25^{\circ} \mathrm{C}\right)$ with compaction process at 5 bar at the initial $2 \mathrm{~h}$. On the other hand, to achieve accurate results of rejection performance, a dead-end filtration with an effective membrane area of $7.54 \mathrm{~cm}^{2}$ was used. The dead-end type was operated at 4 bar for $2 \mathrm{~h}$ at room temperature $\left(23-25^{\circ} \mathrm{C}\right)$.

The permeate flux was measured through weighing the permeate on an electronic balance for each time interval. Thus, by using equation 2 [40], the pure water flux was determined:

$J=\frac{m}{A \Delta t}$

where $m$ is the weight of the permeate water $(\mathrm{kg}), A$ is the effective membrane area $\left(\mathrm{m}^{2}\right)$, and $\Delta t$ is the permeation time (h). Furthermore, the rejection performances were checked by both organic solutions (PEO-100000, PVP-55000, PEG-35000) and protein solution (BSA-67000) with $1 \mathrm{~g} / \mathrm{L}$ concentration. The rejection value [37] was calculated using equation 3, as follows: $R(\%)=\frac{C_{f}-C_{p}}{C_{f}} \times 100$

where $C_{f}$ and $C_{p}$ represent the concentrations of the feed and permeate solutions, respectively. The concentrations were measured using a total organic carbon (TOC) analyzer (TOC-5000 (A) Shimadzu, Japan) and a UV-Vis spectrometer (protein concentration using UV/vis Spectrophotometer Optizen POP QX5w4407-109038-00, Republic of Korea).

Furthermore, to check the fouling resistance of the membranes, BSA solution (150 ppm) was filtered for $1 \mathrm{~h}\left(\mathrm{~J}_{\mathrm{f}}\right)$ after the DI water filtration $\left(\mathrm{J}_{\mathrm{wv}}\right)$ has been completed. The process was followed by washing of the fouled membrane with DI water at a velocity of $0.6 \mathrm{~cm} / \mathrm{s}$. Further, the DI water once again was filtered through the cleaned membrane $\left(\mathrm{J}_{\mathrm{wc}}\right)$. By several 
parameters, antifouling properties were calculated through flux recovery ratio (FRR), total flux loss $\left(R_{t}\right)$, reversible fouling ratio $\left(R_{r}\right)$ and irreversible fouling ratio $\left(R_{i r}\right)$ formulas [2], as follows:

$$
\begin{aligned}
& F R R(\%)=\frac{J w c}{J w v} \\
& R_{t}(\%)=\frac{J w v-J f}{J w v} \\
& R_{r}(\%)=\frac{J w c-J f}{J w v} \times 100 \\
& R_{i r}(\%)=\frac{J w v-J w c}{J w v} \times 100 \\
& R_{t}(\%)=R_{r}+R_{i r}
\end{aligned}
$$

\section{Results and Discussion}

\subsection{Characterization of polydopamine-coated MWNT}

Figure 2 shows the TEM images of the pristine and Pdop-MWNTs. The images portrayed similar MWNT structures, however, the Pdop-MWNTs showed thicker surfaces, which are attributed to the Pdop coating. As shown in Fig. 2(b), the thickness of Pdop coating was estimated to be around $7 \mathrm{~nm}$ after $16 \mathrm{~h}$ of coating process. However, a few uncoated MWNTs were still noticeable even after the coating process. This could be due to the lack of stirrer velocity during the coating process of MWNTs, which were not enough to disentangle them in the medium. The increase of MWNT's sonication time before coating process can overcome this distanglement problem.

To further check the successful coating of Pdop on MWNTs, FTIR analysis was carried out. FTIR spectra of Pdop-MWNT (Fig. 3) showed similar peaks with the spectra of Pdop only, which indicated that Pdop was successfully coated on the MWNTs [41,42]. The MWNT showed a peak at $3457 \mathrm{~cm}^{-1}$, which is attributed to the hydroxyl groups, $\mathrm{OH}^{-}$of the pristine MWNT [43]. The presence of $\mathrm{OH}^{-}$for pristine MWNT indicated that there was a little acid group on the MWNT surface while the existence of $\mathrm{OH}^{-}$shown by the coated MWNTs was due to the affinity between Pdop aromatic rings and pristine MWNT sidewalls [42]. Furthermore, the aromatic rings occurred at $1636.3 \mathrm{~cm}^{-1}$ for pristine MWNTs, while for Pdop-MWNTs, they occurred at 1602, 1285, and $1505 \mathrm{~cm}^{-1}$. Similar with Pdop, the amine groups of Pdop-MWNTs were obtained at $1505 \mathrm{~cm}^{-1}$. 
The successful formation and interfacial interaction of Pdop-coating on the MWNT surface were also proven by Raman spectroscopy analysis as shown in Figure 4. Two distinct peaks can be seen for the pristine MWNT, showing the D $\left(1328 \mathrm{~cm}^{-1}\right)$ and $\mathrm{G}\left(1564 \mathrm{~cm}^{-1}\right)$ bands, which are attributed to the disordered and ordered structure of carbon materials. The Pdop-MWNT showed peaks as the sum features of MWNT and Pdop [41]. The $I_{D} / I_{G}$ ratio (intensity ratio of D and G bands) obtained by the Pdop-MWNT was 0.92, which indicated that the structural defect of material was considerably low $[44,45]$. This could be attributed to the role of Pdop in increasing the mechanical structure of MWNT.

Furthermore, the absorbance intensity of the MWNTs in various solutions was measured in order to check the dispersibility provided by the Pdop coating. Figure 5 shows that PdopMWNT resulted to higher aqueous stability in water compared to the uncoated MWNT (pristine MWNT) [46]. Marked in the range of 200-300 nm, the strong absorbance exhibited a well-dispersed coated MWNT which indicated that Pdop could facilitate the disentanglement of MWNT bundles to form stable dispersion [47]. Furthermore, similar with absorbance in water (Figure 5 a), Pdop-MWNT showed higher absorbance compared to pristine MWNT [7,48] in NMP solvent (Figure 5b). The peak at $270 \mathrm{~nm}$ pointed out the existence of Pdop on the MWNT surface [7,26,46,49,50,51]. Based on the explanation above, it is predicted that the Pdop-MWNTs would obtain fine dispersion in NMP solvent.

\subsection{Characterization of Pdop-MWNT/Psf membrane}

First, the rheological properties of the casting solution were investigated through measuring their viscosity which has a direct correlation to the dispersion quality of a nanomaterial in polymer [52]. Under constant temperature of $25^{\circ} \mathrm{C}$, the Psf solution viscosity increased with the addition of Pdop-MWNTs in the solution (Figure 6) [37,53]. This could be due to the occurrence of good interaction between MWNTs and the polymer. Moreover, the viscosity was higher with the higher loading of Pdop-MWNT [53]. The MWNT concentration was found to have a linear function with viscosity [52], which is attributed to the strong network of polymer and MWNTs that in turn played a role in the morphology of the membranes during the phase inversion process [53]. A steep increase in viscosity was observed at the highest tested concentration of $0.5 \mathrm{wt} \%$. Therefore, it was presumed that the rheological percolation threshold of mixed casting solution was between 0.3 and $0.5 \mathrm{wt} \%$. The threshold of $0.5 \mathrm{wt} \%$ predictively preferred the interaction of MWNT-MWNT rather than MWNT-polymer 
which led to the entanglement of MWNT-MWNT or less dispersion of MWNT in the polymer [52]. Inversely, at the lower concentration, non-interacting nanotubes were homogenously dispersed in the polymer matrix showing good stability against aggregation [52]. On the other hand, the enlarged viscosity was possible to jam the kinetic diffusion following either the rheological hindrance or a delayed exchange between solvent and non-solvent in the phase inversion process $[37,53]$. Therefore, it was decided to use a lower concentration of MWNTs to be loaded to the polymer matrix to provide the domination of polymer-MWNT interaction with the intention of preventing either the entanglement of MWNT-MWNT or delayed exchange of the solvent-non solvent process.

Furthermore, based on the FTIR results (Figure 7), it was observed that Psf polymer and Pdop-MWNTs were succesfully bound. It showed that all the composite membranes had the same basic structure of Psf (Fig. 7a) [3]. Polysulfone, which essentially contains the sub-unit aryl- $\mathrm{SO}_{2}$-aryl and $\mathrm{S}=\mathrm{O}$ defined sulfone group [3,37], was found in the bend spectra of all membranes. Hydroxyl groups occurred in both base and modified membranes at the peak of around $2976 \mathrm{~cm}^{-1}$, which were possibly attributed to the Psf and Pdop characteristics. The N-H peak specific to Pdop identity only existed in the modified membrane at $1579 \mathrm{~cm}^{-1}$ (Fig. $7 \mathbf{b}$ and 7c) [54,55]. Since Psf and Pdop have almost similar chemical structures, it is difficult to determine the source of the appeared aromatic rings or hydroxyl group vibrations. Thus, it is assumed that the successful modified membrane was shown by the higher peak obtained.

Contact angle is a quantitative measurement of the wettability of the membrane [56]. As shown in Table 2, the CA of membranes decreased when the MWNTs were added into the polymer matrix, which indicated that the presence of coated-MWNT in the composite has increased the hydrophilicity of the membranes. The improvement in surface hydrophilicity of the membranes especially at 0.05 and $0.1 \mathrm{wt} \%$ MWNTs could be attributed to the influence of the hydroxyl $[40,53]$ and amine groups [25,57] attached on the MWNTs. Moreover, during the phase inversion process, hydrophilic MWNTs migrated spontaneously to the membrane/water interface to reduce the interfacial energy $[15,19,58]$. However, at higher MWNT loadings (i.e., 0.3 and $0.5 \mathrm{wt} \%$ ), the CA was found to increase. It was possible that the viscosity of MWNTs in the membrane was increased due to the steric hindrance and electrostatic interaction between either coated MWNTs and Psf, or between coated MWNTs themselves. This possibility made irregular collocation in the membrane during phase inversion [54]. Especially, at higher MWNT loading ( $>0.3 \mathrm{wt} \%$ ), a rougher surface could have been formed due to some formation of beads or protrusion of MWNTs on the surface resulting to increased CA. The porosity of the 
membranes, (Table 2), revealed that the composite membranes possessed higher porosity than the base membrane. It might be due to the fast exchange of solvent and non-solvent in the phase inversion process $[19,58]$. However, inversed results were obtained at more than $0.1 \%$ MWNT loading where a decreased porosity was observed. This decrease is attributed to the delayed phase separation leading to a denser structure in the sublayer of the membranes [19]. Furthermore, to describe the pore size or tightness of the membrane surface, the MWCO of membranes [39] was analyzed (Table 2). The result showed that the MWCO of the base membrane was smaller than those of the composite membranes, which means that higher tightness or smaller pore size was achieved by the base membrane [19]. The addition of coated MWNTs into polymer matrix has increased the surface pore size as confirmed in the SEM images in Figure 8.

The cross-sectional morphologies of the base and composite membranes were characterized by SEM imaging (Figure 9). In general, all membranes showed anisotropic or asymmetric structure consisting of dense top layer and porous sublayer. The porous substrate showed large finger-like cavities or macrovoid structure extending from just under the selective skin layer to the bottom surface of the membrane [54,59]. According to Figure 9, the influence of the existence of MWNTs in polymer matrix made insignificant change to the membrane structure. However, the sublayer of the mixed membranes showed an intense nodular structure compared to the base membrane. The intense nodular structure is attributed to the effect of the hydrophilicity of the coated MWNT which led to the fast exchange of solvent and non-solvent in the phase inversion process and in turn conducted the interaction between components in the casting solution and phase inversion kinetics [15].

\subsection{Performance of Pdop-MWNTs/Psf membrane}

\subsubsection{Permeability}

The role of coated MWNTs as fillers in a polymer matrix could be observed in the ultrafiltration performance result. Table 3 shows permeation flux results of the different neat and composite membranes at various operating pressures for pure water and BSA solution. From the table, it can be seen that the pure water flux of the membranes was improved with the addition of hydrophilic MWNTs for all operating pressures of 1 to 4 bar [60,61,62]. This improved flux behavior can be explained by two main reasons. First, the addition of PdopMWNTs in Psf membrane has enhanced the hydrophilicity of the membrane as proven by the 
CA measurement data (down to $42^{\circ}$ at $0.1 \mathrm{wt} \%$ Pdop-MWNTs/Psf). It was seen that the static water CA has decreased with the addition of MWNTs. Second, the hydrophilicity improvement escalated the exchange of solvent and non-solvent in the phase inversion process. This improvement led to the regular collocation of MWNT in the membrane, wherein due to its hydrophilicity, has helped increase the water flux [19,63]. In addition, another fact was that the presence of coated MWNT in the matrix provided higher porosity compared to the base membrane, which promoted more water passage through the membrane. The maximum pure water flux was reached using 0.1 wt\% MWNT. Beyond this MWNT loading, the pure water flux was observed to decline. The results in Table $\mathbf{3}$ are consistent with the characterization results presented in the previous section. At higher MWNT loadings (0.3 and $0.5 \mathrm{wt} \%)$, lower porosity and higher CAs were observed which could have affected the permeate flux (Table 3). Additionally, the large viscosity of MWNTs in the membrane could have led to the steric hindrance and electrostatic interactions of MWNT-MWNT and polymer-MWNT. Therefore, either the cluster phenomenon or the delayed exchange of solvent and non-solvent could not be prevented during the phase inversion process $[54,61,63]$. It was closely related to the increasing viscosity as explained before (Figure 6). Furthermore, the effect of pressure on pure water flux (permeability) was also analyzed (Table 3). The pure water flux was found to increase with the increase of pressure as also observed by other studies [37,64]. This confirmed that the physical properties of the membranes such as pore size and porosity had a direct correlation with pressure in generating high pure water flux especially in a filtration system [37,59]. The lower BSA rejection of the membrane with highest Pdop-MWNT content (i.e., $0.5 \mathrm{wt} \%$ ) could be attributed to its increased surface pore size as indicated in Table 2. The agglomeration of PdopMWNTs at this high content has led to irregularities on the surface, and big pore sizes that could allow more BSA molecules to pass through thereby lowering its rejection performance.

\subsubsection{Antifouling property}

As earlier reported, polydopamine has a big influence for improving antifouling properties of membranes [24,57]. The tests were performed using a dead-end stirrer cell (at 300 rpm) and a BSA feed solution (1000 ppm) to find the rejection ability and flux of membranes. In Table 3, it is shown that the composite membranes have higher improvement for water permeability. As previously discussed, this was attributed to the hydrophilicity given by PdopMWNTs. In the case of rejection performance, all the membranes showed high rejection, i.e., above 90\% (Table 3). The reason might be due to the high molecules of BSA that were not 
allowed to pass the membrane surfaces [19]. Overall, the composite membranes showed higher performances on both flux and rejection compared to the base membrane. It could be also due to the hydrophilicity [24,57] and to the negative charge provided by Pdop on the membrane $[35,36]$. The hydrophilicity increased the flux while at the same time the composite membranes gave repulsive interaction to the protein molecule [14,65]. From the present results, Pdop shows a potential role to address the trade-off between permeability and permselectivity (i.e., flux and rejection performances) in an ultrafiltration process.

The effectiveness of Pdop-MWNTs as filler materials in the polymer matrix in improving the antifouling properties of membranes was evaluated with the following parameters: flux recovery ratio (FRR), reversible resistance $\left(R_{r}\right)$, and irreversible resistance $\left(R_{i r}\right)$ parameters. During the filtration of 150 ppm BSA solution, a decreasing flux trend was observed, which indicated fouling formation on the membranes (Fig. 10, middle curves) [58]. BSA molecules were suspected to be deposited on the membrane surface and entrapped in the pores hampering the water flow.

FRR provides information on the recycling properties of the membrane [14], i.e., the higher FRR value, the better antifouling property, and the results are shown in Table 4. It shows that the flux recovery of mixed membranes is higher than that of the base membrane. It means that the filtration performance of the composite membranes was enhanced when they were exposed to the protein solution [15]. Moreover, the $0.1 \mathrm{wt} \%$ Pdop-MWNT/Psf membrane obtained the highest FRR, i.e., 82.57\%, which indicates that the antifouling property was better for this membrane. Meanwhile, the lowest FRR occurred using the base membrane, i.e., at $44.62 \%$.

$\mathrm{R}_{\mathrm{t}}$ is attributed to the effect of total protein fouling, which is due to the adsorption and deposition of protein on the membrane, and the $\mathrm{R}_{\mathrm{t}}$ results are shown in Table 4. Lower total flux loss can be interpreted as an improvement of the antifouling property of a membrane $[14,40,60]$. The result showed that the composite membranes had generally lower $R_{t}$ values than the base membrane. $R_{t}$ itself consists of two types of fouling, namely: reversible fouling $\left(\mathrm{R}_{\mathrm{r}}\right)$ and irreversible fouling $\left(\mathrm{R}_{\mathrm{ir}}\right)$. Reversible fouling indicates that the adsorption of protein on the membrane could be reversed or removed by simple hydraulic cleaning [60]. On the contrary, irreversible fouling refers to the stable adsorption of protein molecules on the membrane surface, or that the entrapment of protein molecules in pores are more difficult to be removed [66]. Based on our experiments, the composite membranes showed higher results of 
$\mathrm{R}_{\mathrm{r}}$ and smaller $\mathrm{R}_{\mathrm{ir}}$ than the base membranes. This suggests that the composite membrane improves the membrane antifouling tendency.

It can be deduced that the existence of Pdop-MWNTs in the membrane has improved the membrane antifouling property. The major factor that plays a significant role in this phenomenon is the hydrophilicity provided by Pdop. As proposed earlier, the hydrophilicity plays an important role in increasing the antifouling properties of the membrane $[14,40,60]$. The fouling tendency was reduced by the repulsive interaction process between both membrane surface and protein molecule (BSA). Therefore, it minimized the entrapment of protein on the membrane pores. As the filtration was conditioned at neutral $\mathrm{pH}$, it was presumed that the BSA was negatively charged [14,60], and the composite membrane surface was also negatively charged because of the presence of Pdop $[67,68]$.

The effectiveness of the MWNT reinforcement was limited to the concentration and dispersion of the MWNTs in the membrane. It can be concluded that $0.1 \mathrm{wt} \%$ MWNT showed the optimum content for improving the membrane antifouling properties. When MWNT concentration was greater than $0.1 \mathrm{wt} \%$, the antifouling properties of the membrane decreased. The excess ratio of MWNTs in the membrane leads to the decrease of the antifouling properties due to the irregular positioning of MWNTs, which results in the degradation of surface properties of the membranes [14]. Therefore, the loading of MWNT which is embedded in the polymer must be carefully considered.

The comparison between the performances of Psf membranes incorporated with PdopMWNTs and with acid-treated MWNTs is detailed in Appendix A (Supplementary material).

\section{Conclusions}

In this study, the effect of polydopamine coating on mutiwalled carbon nanotubes (MWNTs) on their dispersibility in polysulfone (Psf) membrane, and the overall permeability, mechanical properties and antifouling performance of the Pdop/MWNT incorporated Psf membrane was investigated. The following are the conclusions drawn from this study:

a) The Pdop-MWNTs mixed with polysulfone (Psf) polymer have addressed the trade-off between rejection and permeability performances for ultrafiltration. While maintaining a high rejection performance (99.88\%), the water permeability was increased (by $19-50 \%$ using 1,000 ppm BSA solution) due to the hydrophilic properties introduced by the Pdopcoated MWNTs in the composite Psf membrane. 
b) The Pdop-coated MWNTs showed improved hydrophilic behavior especially at 0.05 and $0.1 \mathrm{wt} \%$ concentration, but beyond that content, the contact angle started to increase. The uniqueness of Pdop which has $\mathrm{OH}^{-}$and $\mathrm{NH}_{2}$ functional groups would be the reason for the improvement in hydrophilic properties.

c) The functionalization derived from the coating process of the Pdop onto the MWNT surface has successfully improved the antifouling properties of the membranes. This is mainly attributed to the improved hydrophilicty of the membrane. The fouling tendency was reduced by the repulsive interaction process between both membrane surface and protein molecule (BSA). Therefore, it minimized the entrapment of protein on the membrane pores. The negatively-charged Pdop could have made the membrane negatively-charged, so that there was a repulsion effect on the BSA, which was also negatively-charged.

d) Furthermore, another advantage of Pdop coating approach is the increased mechanical strength of coated MWNT, which led to improved strength of the membrane. The sticky property of Pdop, which is inspired by the natural stickiness of mussels helped in its adhesion to the hydrophobic substrate leading to increased mechanical properties.

e) The optimum dose for overall enhanced membrane properties and ultrafiltration performance in the present study was determined to be $0.1 \mathrm{wt} \%$ of Pdop-MWNTs. The present Pdop-MWNT/Psf membrane with high mechanical strength showed good potential for sustainable long term ultrafiltration application.

\section{Acknowledgements}

We are grateful for the suppport of a fund from the K-Water Research \& Business Project grant (K_RBP_1) to conduct this research. The authors also acknowledge the grants from the UTS Chancellor's Postdoctoral Research Fellowship and ARC Future Fellowship (FT140101208).

\section{References}

[1] W.E. Federation, Membrane Systems for Wastewater Treatment, McGraw-Hill, USA, 2006. 
[2] F. Peng, L. Lu, H. Sun, Y. Wang, J. Liu, Z. Jiang, Hybrid organic-inorganic membrane: solving the tradeoff between permeability and selectivity, Chem Mater, 17 (2005) 6790-6796.

[3] Q.G. Zhang, Q.L. Liu, F.F. Shi, Y. Xiong, Structure and permeation of organic-inorganic hybrid membranes composed of poly (vinyl alcohol) and polysilisesquioxane, J. Mater. Chem., 18 (2008) 4646-4653.

[4] L.D. Tijing, Y.C. Woo, J.-S. Choi, S. Lee, S.-H. Kim, H.K. Shon, Fouling and its control in membrane distillation-A review, Journal of Membrane Science 475 (2015) 215-244.

[5] S. Iijima, Helical microtubules of graphitic carbon, Nature, 354 (1991) 56-58.

[6] K.H. Chan, E.T. Wong, M.I. Khan, A. Idris, N.M. Yusof, Fabrication of polyvinylidene difluoride nano-hybrid dialysis membranes using functionalized multiwall carbon nanotube for polyethylene glycol (hydrophilic additive) retention, J. Ind. Eng. Chem., 20 (2014) 3744-3753.

[7] L.D. Tijing, C.-H. Park, W.L. Choi, M.T.G. Ruelo, A. Amarjargal, H.R. Pant, I.-T. Im, C.S. Kim, Characterization and mechanical performance comparison of multiwalled carbon nanotube/polyurethane composites fabricated by electrospinning and solution casting, Compos Part B: Eng, 44 (2013) 613-619.

[8] V.K.K. Upadhyayula, S. Deng, M.C. Mitchell, G.B. Smith, Application of carbon nanotube technology for removal of contaminants in drinking water: A review, Sci. Total Environ., 408 (2009) 113.

[9] C.H. Ahn, Y. Baek, C. Lee, S.O. Kim, S. Kim, S. Lee, et al., Carbon nanotube-based membranes: Fabrication and application to desalination, Journal of Industrial and Engineering Chemistry 18(5) (2012) 1551-1559.

[10] R. Das, M.E. Ali, S.B.A. Hamid, S. Ramakrishna, Z.Z. Chowdhury, Carbon nanotube membranes for water purification: A bright future in water desalination, Desalination, 336 (2014) 97-109.

[11] L.A. Nezam El-Din, A. El-Gendi, N. Ismail, K.A. Abed, A.I. Ahmed, Evaluation of cellulose acetate membrane with carbon nanotubes additives, J. Ind. Eng. Chem., 26 (2015) 259-264.

[12] Z. Rahimi, A.A.L. Zinatizadeh, S. Zinadini, Preparation of high antibiofouling amino functionalized MWCNTs/PES nanocomposite ultrafiltration membrane for application in membrane bioreactor, Journal of Industrial and Engineering Chemistry 29 (2015) 366-374.

[13] B. Fei, B. Qian, Z. Yang, R. Wang, W.C. Liu, C.L. Mak, J.H. Xin, Coating carbon nanotubes by spontaneous oxidative polymerization of dopamine, Carbon, 46 (2008) 1795-1797.

[14] A. Rahimpour, M. Jahanshahi, S. Khalili, A. Mollahosseini, A. Zirepour, B. Rajaeian, Novel functionalized carbon nanotubes for improving the surface properties and performance of polyethersulfone (PES) membrane, Desalination, 286 (2012) 99-107. 
[15] V. Vatanpour, S.S. Madaeni, R. Moradian, S. Zinadini, B. Astinchap, Fabrication and characterization of novel antifouling nanofiltration membrane prepared from oxidized multiwalled carbon nanotube/polyethersulfone nanocomposite, J Membrane Sci, 375 (2011) 284-294.

[16] N. Phao, E.N. Nxumalo, B.B. Mamba, S.D. Mhlanga, A nitrogen-doped carbon nanotube enhanced polyethersulfone membrane system for water treatment, Phys Chem Earth, Parts A/B/C, 66 (2013) 148156.

[17] K.A. Wepasnick, B.A. Smith, K.E. Schrote, H.K. Wilson, S.R. Diegelmann, D.H. Fairbrother, Surface and structural characterization of multi-walled carbon nanotubes following different oxidative treatments, Carbon, 49 (2011) 24-36.

[18] C. Dong, A.S. Campell, R. Eldawud, G. Perhinschi, Y. Rojanasakul, C.Z. Dinu, Effects of acid treatment on structure, properties and biocompatibility of carbon nanotubes, Appl. Surf. Sci., 264 (2013) 261-268.

[19] E. Celik, L. Liu, H. Choi, Protein fouling behavior of carbon nanotube/polyethersulfone composite membranes during water filtration, Water Res., 45 (2011) 5287-5294.

[20] M. Olek, J. Ostrander, S. Jurga, H. Möhwald, N. Kotov, K. Kempa, M. Giersig, Layer-by-layer assembled composites from multiwall carbon nanotubes with different morphologies, Nano Lett., 4 (2004) 1889-1895.

[21] L. Liu, B. Shao, F. Yang, Polydopamine coating - Surface modification of polyester filter and fouling reduction, Sep. Purif. Technol., 118 (2013) 226-233.

[22] H. Lee, S.M. Dellatore, W.M. Miller, P.B. Messersmith, Mussel-inspired surface chemistry for multifunctional coatings, Science, 318 (2007) 426-430.

[23] S.H. Ku, J. Ryu, S.K. Hong, H. Lee, C.B. Park, General functionalization route for cell adhesion on non-wetting surfaces, Biomater, 31 (2010) 2535-2541.

[24] P. Podsiadlo, Z. Liu, D. Paterson, P.B. Messersmith, N.A. Kotov, Fusion of seashell nacre and marine bioadhesive analogs: High - strength nanocomposite by layer - by - layer assembly of clay and L-3, 4 - Dihydroxyphenylalanine Polymer, Adv. Mater., 19 (2007) 949-955.

[25] B.D. McCloskey, H.B. Park, H. Ju, B.W. Rowe, D.J. Miller, B.D. Freeman, A bioinspired foulingresistant surface modification for water purification membranes, J Membrane Sci, 413 (2012) 82-90.

[26] S. Kasemset, A. Lee, D.J. Miller, B.D. Freeman, M.M. Sharma, Effect of polydopamine deposition conditions on fouling resistance, physical properties, and permeation properties of reverse osmosis membranes in oil/water separation, J Membrane Sci, 425 (2013) 208-216. 
[27] H.Y. Son, I. Kim, Y.S. Nam, On-surface synthesis of metal nanostructures on solid and hydrated polymer nanofibers coated with polydopamine, Journal of Industrial and Engineering Chemistry (In press, 2015) doi:10.1016/j.jiec.2015.05.025.

[28] J.-H. Jiang, L.-P. Zhu, H.-T. Zhang, B.-K. Zhu, Y.-Y. Xu, Improved hydrodynamic permeability and antifouling properties of poly (vinylidene fluoride) membranes using polydopamine nanoparticles as additives, J Membrane Sci, 457 (2014) 73-81.

[29] S. Mulyati, R. Takagi, A. Fujii, Y. Ohmukai, H. Matsuyama, Simultaneous improvement of the monovalent anion selectivity and antifouling properties of an anion exchange membrane in an electrodialysis process, using polyelectrolyte multilayer deposition, J Membrane Sci, 431 (2013) 113120.

[30] H. Lee, J. Rho, P.B. Messersmith, Facile conjugation of biomolecules onto surfaces via mussel adhesive protein inspired coatings, Adv. Mater., 21 (2009) 431-434.

[31] A. Bourmaud, J. Riviere, A. Le Duigou, G. Raj, C. Baley, Investigations of the use of a musselinspired compatibilizer to improve the matrix-fiber adhesion of a biocomposite, Polym Test, 28 (2009) 668-672.

[32] X. Song, L. Wang, C.Y. Tang, Z. Wang, C. Gao, Fabrication of carbon nanotubes incorporated double-skinned thin film nanocomposite membranes for enhanced separation performance and antifouling capability in forward osmosis process, Desalination 369 (2015) 1-9.

[33] L. Huang, J.T. Arena, S.S. Manickam, X. Jiang, B.G. Willis, J.R. McCutcheon, Improved mechanical properties and hydrophilicity of electrospun nanofiber membranes for filtration applications by dopamine modification, J Membrane Sci, 460 (2014) 241-249.

[34] D.R. Dreyer, D.J. Miller, B.D. Freeman, D.R. Paul, C.W. Bielawski, Elucidating the structure of poly (dopamine), Langmuir, 28 (2012) 6428-6435.

[35] J. Wang, L. Xiao, Y. Zhao, H. Wu, Z. Jiang, W. Hou, A facile surface modification of Nafion membrane by the formation of self-polymerized dopamine nano-layer to enhance the methanol barrier property, J Power Sources, 192 (2009) 336-343.

[36] Q. Liu, B. Yu, W. Ye, F. Zhou, Highly Selective Uptake and Release of Charged Molecules by pH - Responsive Polydopamine Microcapsules, Macromol Biosci, 11 (2011) 1227-1234.

[37] B. Yu, J. Liu, S. Liu, F. Zhou, Pdop layer exhibiting zwitterionicity: a simple electrochemical interface for governing ion permeability, Chem. Commun., 46 (2010) 5900-5902.

[38] J.-H. Choi, J. Jegal, W.-N. Kim, Fabrication and characterization of multi-walled carbon nanotubes/polymer blend membranes, J Membrane Sci, 284 (2006) 406-415. 
[39] Q.-Z. Zheng, P. Wang, Y.-N. Yang, D.-J. Cui, The relationship between porosity and kinetics parameter of membrane formation in PSF ultrafiltration membrane, J Membrane Sci, 286 (2006) 7-11.

[40] M. Mulder, Basic Principles of Membrane Technology Second Edition, Kluwer Academic Pub, 1996.

[41] Y. Mansourpanah, S. Madaeni, A. Rahimpour, M. Adeli, M. Hashemi, M. Moradian, Fabrication new PES-based mixed matrix nanocomposite membranes using polycaprolactone modified carbon nanotubes as the additive: property changes and morphological studies, Desalination, 277 (2011) 171177.

[42] Y.-Q. Wang, Y.-L. Su, Q. Sun, X.-L. Ma, Z.-Y. Jiang, Generation of anti-biofouling ultrafiltration membrane surface by blending novel branched amphiphilic polymers with polyethersulfone, J Membrane Sci, 286 (2006) 228-236.

[43] Y. Zhao, Z. Xu, M. Shan, C. Min, B. Zhou, Y. Li, B. Li, L. Liu, X. Qian, Effect of graphite oxide and multi-walled carbon nanotubes on the microstructure and performance of PVDF membranes, Sep. Purif. Technol., 103 (2013) 78-83.

[44] F. Bernsmann, V. Ball, F. Addiego, A. Ponche, M. Michel, J.J.d.A. Gracio, V. Toniazzo, D. Ruch, Dopamine- Melanin Film Deposition Depends on the Used Oxidant and Buffer Solution, Langmuir, 27 (2011) 2819-2825.

[45] G. Wang, H. Huang, G. Zhang, X. Zhang, B. Fang, L. Wang, Dual amplification strategy for the fabrication of highly sensitive interleukin-6 amperometric immunosensor based on poly-dopamine, Langmuir, 27 (2010) 1224-1231.

[46] B. Scheibe, E. Borowiak-Palen, R.J. Kalenczuk, Oxidation and reduction of multiwalled carbon nanotubes_-preparation and characterization, Mater. Charact., 61 (2010) 185-191.

[47] M. Zdrojek, W. Gebicki, C. Jastrzebski, T. Melin, A. Huczko, Studies of multiwall carbon nanotubes using Raman spectroscopy and atomic force microscopy, Solid State Phenomena, 99 (2004) 265-268.

[48] D. Zhong, Q. Yang, L. Guo, S. Dou, K. Liu, L. Jiang, Fusion of nacre, mussel, and lotus leaf: bioinspired graphene composite paper with multifunctional integration, Nanoscale, 5 (2013) 5758-5764.

[49] M. Lin, H. Huang, Y. Liu, C. Liang, S. Fei, X. Chen, C. Ni, High loading of uniformly dispersed Pt nanoparticles on polydopamine coated carbon nanotubes and its application in simultaneous determination of dopamine and uric acid, Nanotechnology, 24 (2013) 065501.

[50] J.-l. Wang, K.-f. Ren, H. Chang, S.-m. Zhang, L.-j. Jin, J. Ji, Facile fabrication of robust superhydrophobic multilayered film based on bioinspired poly (dopamine)-modified carbon nanotubes, PCCP, 16 (2014) 2936-2943. 
[51] H.-P. Peng, R.-P. Liang, L. Zhang, J.-D. Qiu, General preparation of novel core-shell heme protein-Au-polydopamine-Fe3O4 magnetic bionanoparticles for direct electrochemistry, J. Electroanal. Chem., 700 (2013) 70-76.

[52] H. Liu, P. Xi, G. Xie, Y. Shi, F. Hou, L. Huang, F. Chen, Z. Zeng, C. Shao, J. Wang, Simultaneous reduction and surface functionalization of graphene oxide for hydroxyapatite mineralization, $\mathrm{J}$ Phys Chem C, 116 (2012) 3334-3341.

[53] Y. Huang, S. Ahir, E. Terentjev, Dispersion rheology of carbon nanotubes in a polymer matrix, Phys Rev B, 73 (2006) 125422.

[54] S. Majeed, D. Fierro, K. Buhr, J. Wind, B. Du, A. Boschetti-de-Fierro, V. Abetz, Multi-walled carbon nanotubes (MWCNTs) mixed polyacrylonitrile (PAN) ultrafiltration membranes, J Membrane Sci, 403 (2012) 101-109.

[55] X. Wei, Z. Wang, J. Wang, S. Wang, A novel method of surface modification to polysulfone ultrafiltration membrane by preadsorption of citric acid or sodium bisulfite, Membr Water Treat, 3 (2012) 35-49.

[56] S. Qiu, L. Wu, X. Pan, L. Zhang, H. Chen, C. Gao, Preparation and properties of functionalized carbon nanotube/PSF blend ultrafiltration membranes, J Membrane Sci, 342 (2009) 165-172.

[57] G. Han, S. Zhang, X. Li, N. Widjojo, T.-S. Chung, Thin film composite forward osmosis membranes based on polydopamine modified polysulfone substrates with enhancements in both water flux and salt rejection, Chem. Eng. Sci., 80 (2012) 219-231.

[58] P. Roach, N.J. Shirtcliffe, M.I. Newton, Progess in superhydrophobic surface development, Soft Matter, 4 (2008) 224-240.

[59] B.D. McCloskey, H.B. Park, H. Ju, B.W. Rowe, D.J. Miller, B.J. Chun, K. Kin, B.D. Freeman, Influence of polydopamine deposition conditions on pure water flux and foulant adhesion resistance of reverse osmosis, ultrafiltration, and microfiltration membranes, Polymer, 51 (2010) 3472-3485.

[60] V. Vatanpour, S.S. Madaeni, R. Moradian, S. Zinadini, B. Astinchap, Novel antibifouling nanofiltration polyethersulfone membrane fabricated from embedding $\mathrm{TiO}_{2}$ coated multiwalled carbon nanotubes, Sep. Purif. Technol., 90 (2012) 69-82.

[61] R.W. Baker, Ultrafiltration, in: Membrane Technology and Applications, John Wiley \& Sons, Ltd, 2004, pp. 237-274.

[62] E. Celik, H. Park, H. Choi, H. Choi, Carbon nanotube blended polyethersulfone membranes for fouling control in water treatment, Water Res., 45 (2011) 274-282. 
[63] E.-S. Kim, G. Hwang, M. Gamal El-Din, Y. Liu, Development of nanosilver and multi-walled carbon nanotubes thin-film nanocomposite membrane for enhanced water treatment, J Membrane Sci, 394 (2012) 37-48.

[64] H. Wu, B. Tang, P. Wu, Novel ultrafiltration membranes prepared from a multi-walled carbon nanotubes/polymer composite, J Membrane Sci, 362 (2010) 374-383.

[65] L. Ricq, J. Pagetti, Inorganic membrane selectivity to ions in relation with streaming potential, J Membrane Sci, 155 (1999) 9-18.

[66] J. Peng, Y. Su, Q. Shi, W. Chen, Z. Jiang, Protein fouling resistant membrane prepared by amphiphilic pegylated polyethersulfone, Bioresour. Technol., 102 (2011) 2289-2295.

[67] L. Zou, I. Vidalis, D. Steele, A. Michelmore, S. Low, J. Verberk, Surface hydrophilic modification of RO membranes by plasma polymerization for low organic fouling, J Membrane Sci, 369 (2011) 420428.

[68] E.M. Van Wagner, A.C. Sagle, M.M. Sharma, Y.-H. La, B.D. Freeman, Surface modification of commercial polyamide desalination membranes using poly (ethylene glycol) diglycidyl ether to enhance membrane fouling resistance, J Membrane Sci, 367 (2011) 273-287. 


\section{Figure and table captions}

Figure 1. Schematic illustration of the (a) UF filtration test cell (cross flow type) and the (b) membrane test cell (dead end type).

Figure 2 TEM images of (a) pristine MWNT and (b) Pdop-MWNT.

Figure 3 FTIR spectra of (a) polydopamine, (b) Pdop-MWNT, and (c) pristine MWNT.

Figure 4 Raman spectra of (a) polydopamine, (b) Pdop-MWNT, and (c) pristine MWNT.

Figure 5 UV-Vis absorption spectra of (1) pristine MWNT, (2) Pdop-MWNT in (a) water and (b) NMP solvent.

Figure 6 Viscosity of Psf solution with various MWNT loadings.

Figure 7 FTIR spectra of (a) Psf (b) 0.1\% and (c) 0.5\% Pdop-MWNT/Psf membranes.

Figure 8 SEM surface images of (a) Psf (base) and (b) 0.1 wt\% Pdop-MWNT/Psf membranes Figure 9 SEM images of the cross section of the (a) base membrane (b) $0.1 \mathrm{wt} \%$ and (c) $0.5 \mathrm{wt} \%$ Pdop-MWNT/Psf membranes

Figure 10 Flux behavior of the different membranes at: 60 minutes of DI water filtration (curves at $\mathrm{t}=0$ to $60 \mathrm{~min}), 60$ minutes of BSA solution $(150 \mathrm{ppm}$ ) filtration (curves at $\mathrm{t}=60$ to $120 \mathrm{~min}$ ), and 60 minutes of DI water filtration after backwash process for 20 minutes (curves at $\mathrm{t}=120$ to $180 \mathrm{~min})$.

Table 1 Composition of solutions containing different loadings of MWNTs for membrane fabrication by phase inversion

Table 2 Contact angle, porosity and MWCO properties of the membranes tested in the present study

Table 3 Pure water flux as a function of operating pressure and BSA solution (1,000 ppm) flux and rejection of base and Pdop-MWNTs/Psf membranes.

Table 4 Antifouling properties of the fabricated membranes 
Table 1 Composition of solutions containing different loadings of MWNTs for membrane fabrication by phase inversion

\begin{tabular}{lccc}
\hline \multirow{2}{*}{ Membrane Type } & \multicolumn{3}{c}{ Ratio (wt\%) } \\
\cline { 2 - 4 } & MWNT & NMP & Psf \\
\hline Base Membrane & 0 & 82 & 18 \\
0.05 wt\% Pdop-MWNT/Psf & 0.05 & 81.95 & 18 \\
0.1 wt\% Pdop-MWNT/Psf & 0.1 & 81.9 & 18 \\
0.3 wt\% Pdop-MWNT/Psf & 0.3 & 81.7 & 18 \\
0.5 wt\% Pdop-MWNT/Psf & 0.5 & 81.5 & 18 \\
\hline
\end{tabular}

Table 2 Contact angle, porosity and MWCO properties of the membranes tested in the present study

\begin{tabular}{l|c|c|c}
\hline Membrane Type & Contact angle $\mathbf{(}^{\circ}$ ) & Porosity (\%) & MWCO (kDa) \\
\hline Base (Psf) & 63.1 & 24.6 & 90 \\
\hline 0.05 wt\% Pdop-MWNTs/Psf & 53.75 & 28.3 & 92 \\
\hline 0.1 wt\% Pdop-MWNTs/Psf & 42.85 & 35.7 & 92 \\
\hline 0.3 wt\% Pdop-MWNTs/Psf & 56.85 & 28.9 & 93 \\
\hline 0.5 wt\% Pdop-MWNTs/Psf & 69 & 27.9 & 96 \\
\hline
\end{tabular}


Table 3 Pure water flux as a function of operating pressure and BSA solution $(1,000$ ppm) flux and rejection of base and Pdop-MWNTs/Psf membranes.

\begin{tabular}{|c|c|c|c|c|c|c|}
\hline \multirow[t]{2}{*}{ Membrane type } & \multicolumn{4}{|c|}{ Pure water flux $\left(\mathrm{kg} / \mathrm{m}^{2} \mathrm{~h}\right)$} & \multicolumn{2}{|c|}{$\begin{array}{c}\text { BSA solution (1,000 ppm; at } \\
4 \text { bar) }\end{array}$} \\
\hline & 1 bar & 2 bar & 3 bar & 4 bar & $\begin{array}{c}\text { Flux } \\
\left(\mathrm{kg} / \mathrm{m}^{2} \mathrm{~h}\right)\end{array}$ & $\begin{array}{l}\text { Rejection } \\
(\%)\end{array}$ \\
\hline Base (Psf) & 27.45 & 49.02 & 88.24 & 168.24 & 16.87 & 99.87 \\
\hline 0.05 wt\% Pdop-MWNTs/Psf & 69.46 & 130.54 & 201.13 & 266.98 & 23.22 & 99.50 \\
\hline 0.1 wt\% Pdop-MWNTs/Psf & 81.27 & 174.22 & 255.05 & 324.67 & 25.27 & 99.21 \\
\hline 0.3 wt\% Pdop-MWNTs/Psf & 53.09 & 99.36 & 147.25 & 232.94 & 21.07 & 99.88 \\
\hline 0.5 wt\% Pdop-MWNTs/Psf & 38.38 & 64.07 & 107.94 & 184.44 & 20.13 & 94.91 \\
\hline
\end{tabular}

Table 4 Antifouling properties of the fabricated membranes

\begin{tabular}{c|c|c|c|c}
\hline Membrane Type & FRR (\%) & $\mathrm{R}_{\mathrm{t}}(\%)$ & $\mathrm{R}_{\mathrm{r}}(\%)$ & $\mathrm{R}_{\mathrm{ir}}(\%)$ \\
\hline Base & 44.6 & 71.0 & 15.6 & 55.4 \\
\hline 0.05 wt\% Pdop-MWNT/Psf & 80.5 & 42.2 & 22.7 & 19.5 \\
\hline $0.1 \mathrm{wt} \%$ Pdop-MWNT/Psf & 82.6 & 40.8 & 23.4 & 17.4 \\
\hline $0.3 \mathrm{wt} \%$ Pdop-MWNT/Psf & 75.2 & 44.1 & 19.3 & 24.8 \\
\hline 0.5 wt\% Pdop-MWNT/Psf & 77.1 & 43.6 & 20.7 & 22.9 \\
\hline
\end{tabular}



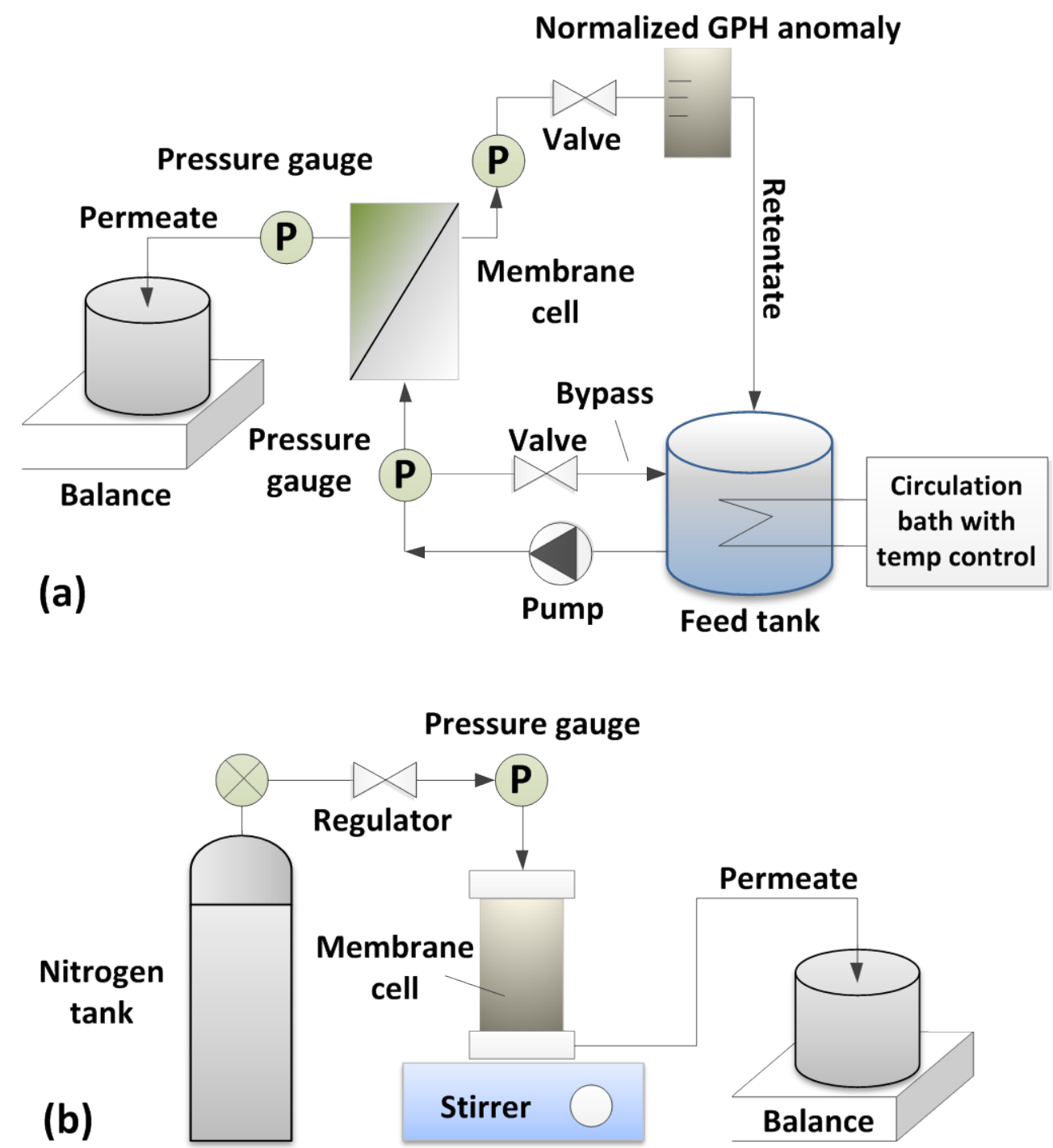

Figure 1. Schematic illustration of the (a) UF filtration test cell (cross flow type) and the (b) membrane test cell (dead end type). 


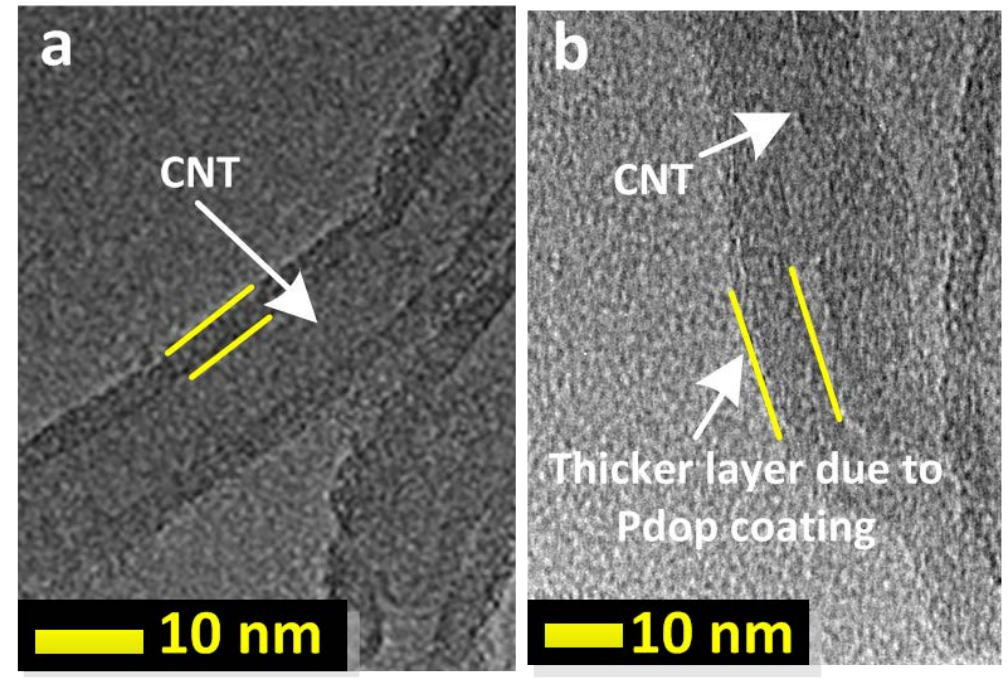

Figure 2 TEM images of (a) pristine MWNT and (b) Pdop-MWNT.

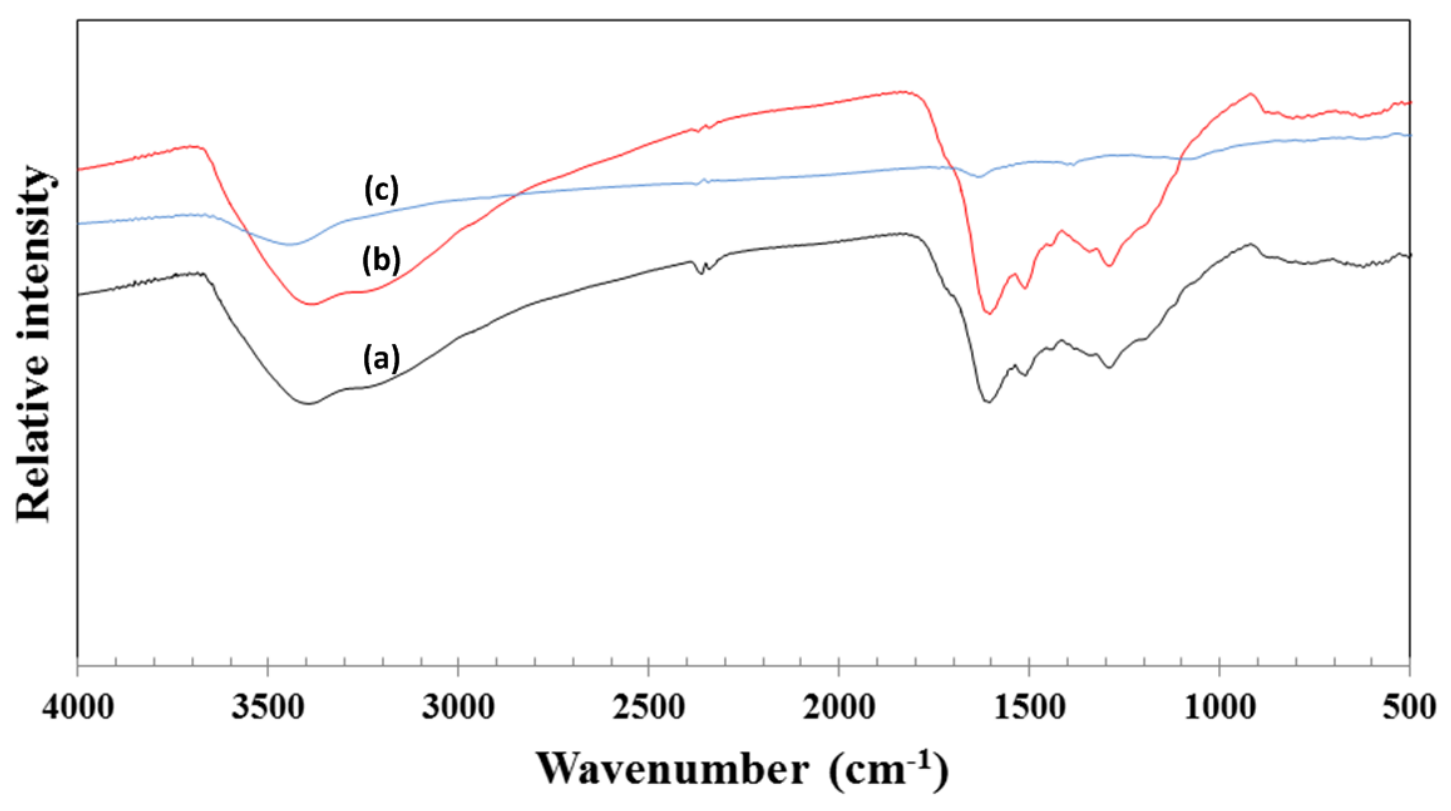

Figure 3 FTIR spectra of (a) polydopamine, (b) Pdop-MWNT, and (c) pristine MWNT. 


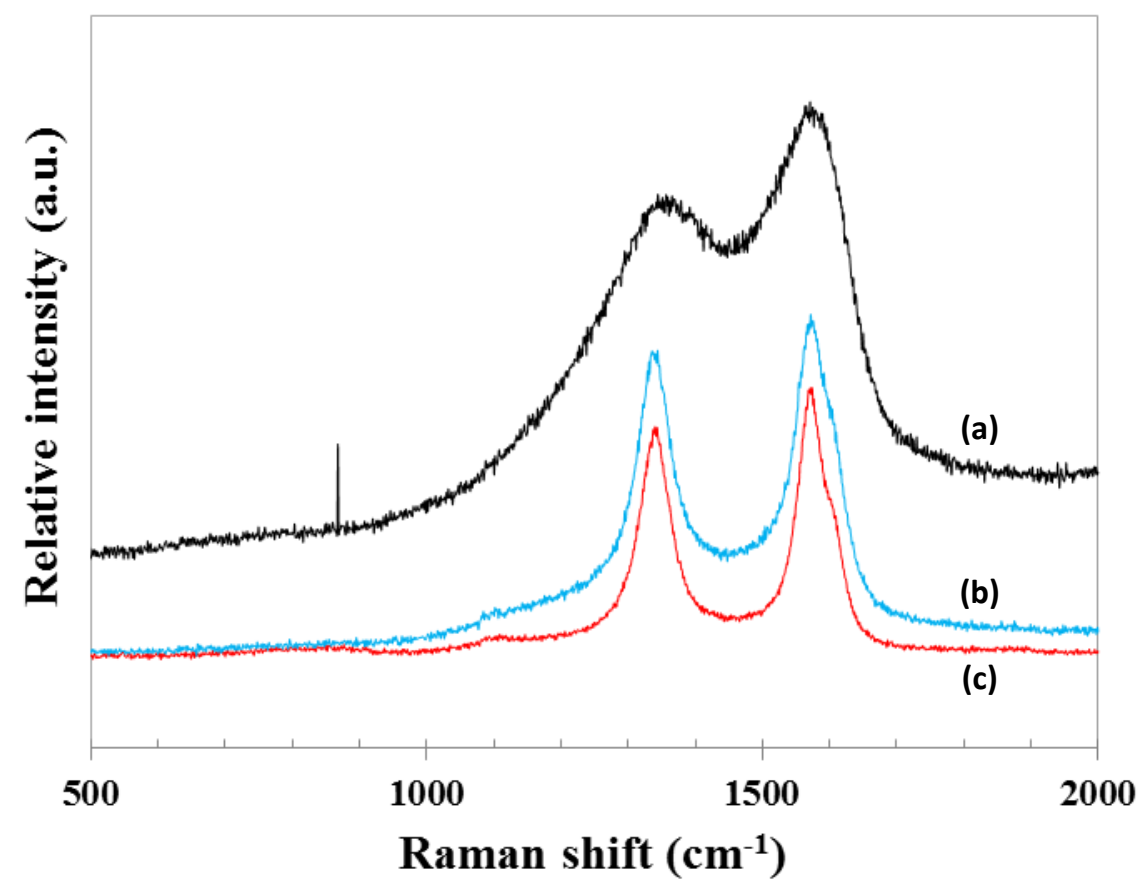

Figure 4 Raman spectra of (a) polydopamine, (b) Pdop-MWNT, and (c) pristine MWNT.
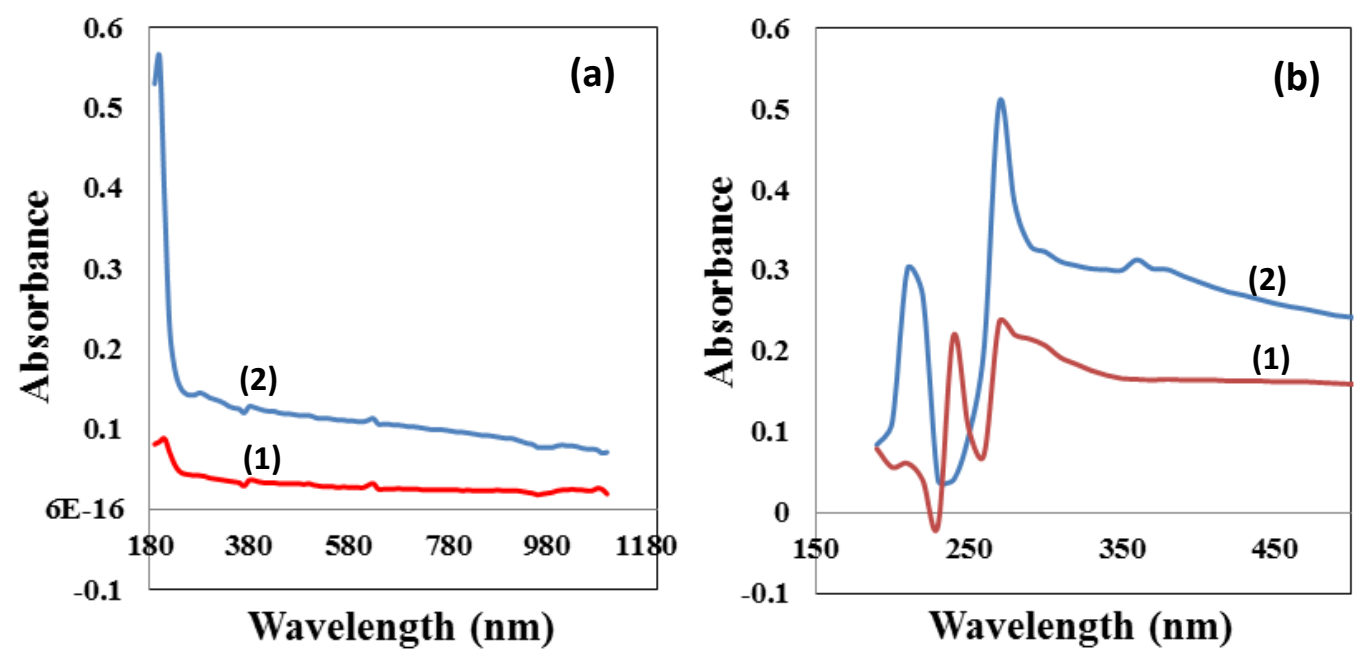

Figure 5 UV-Vis absorption spectra of (1) pristine MWNT, (2) Pdop-MWNT in (a) water and (b) NMP solvent. 


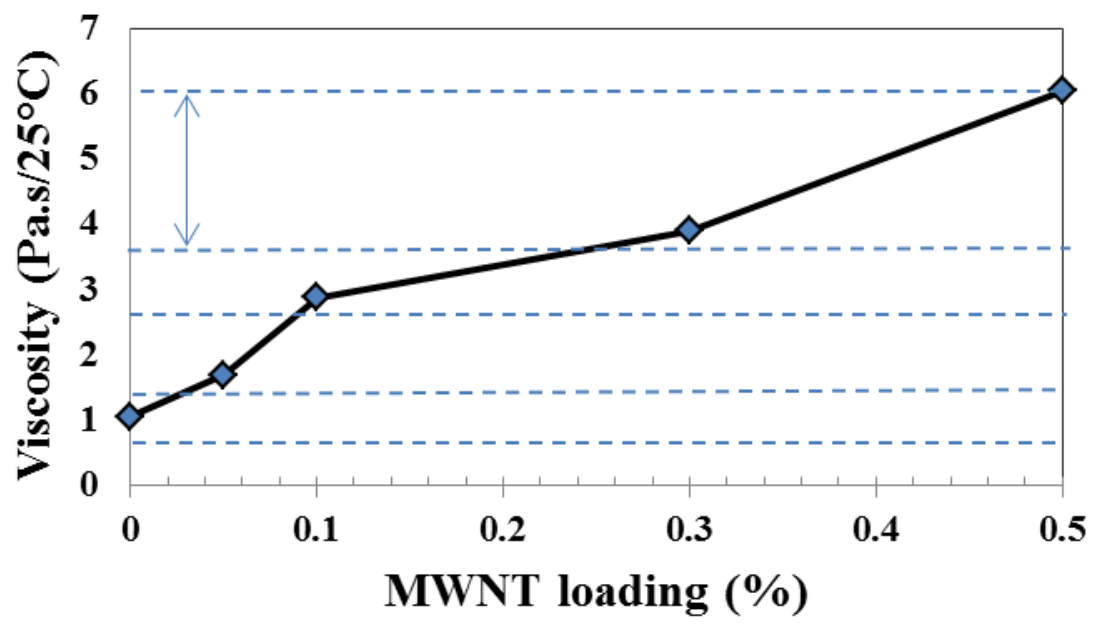

Figure 6 Viscosity of Psf solution with various MWNT loadings.

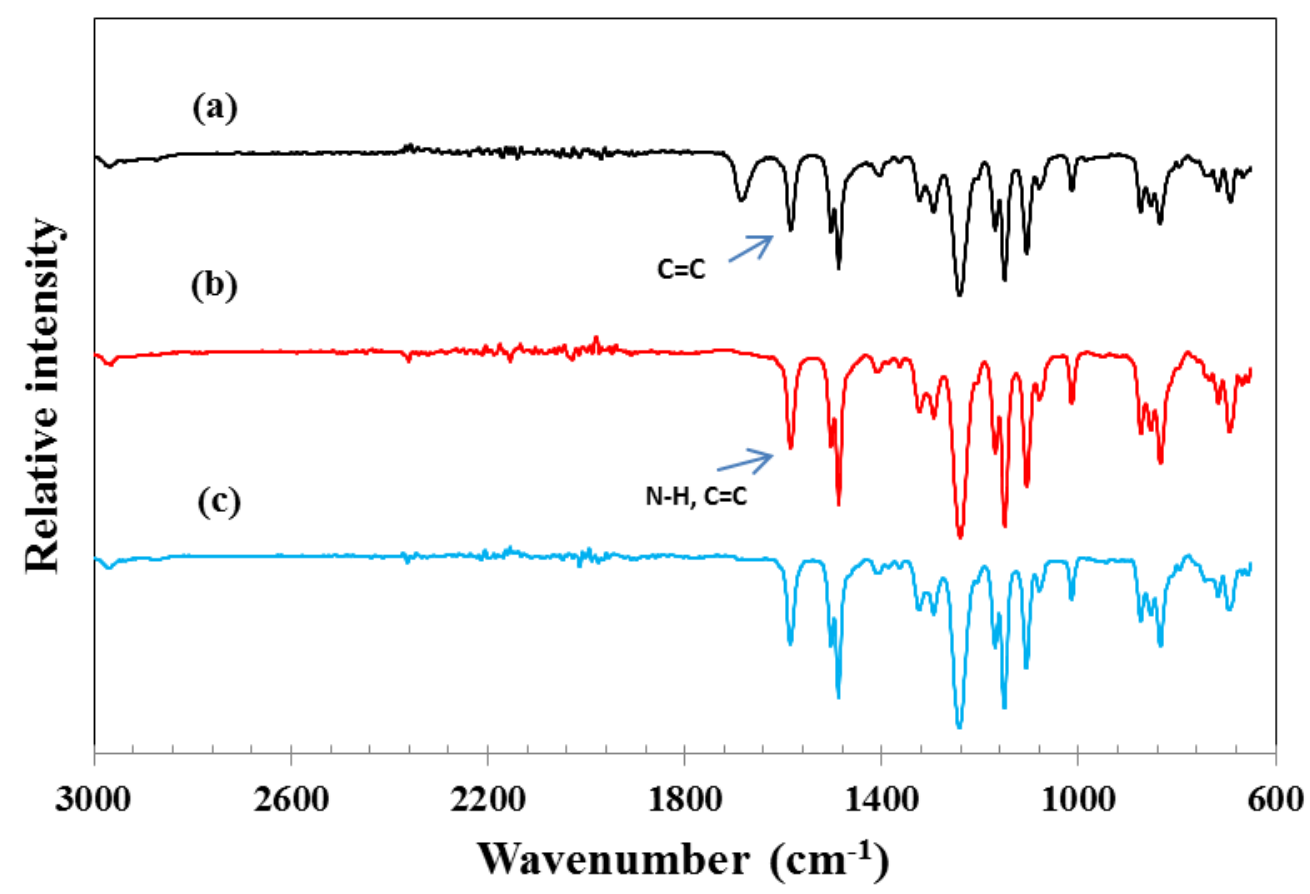

Figure 7 FTIR spectra of (a) Psf (b) 0.1\% and (c) 0.5\% Pdop-MWNT/Psf membranes. 

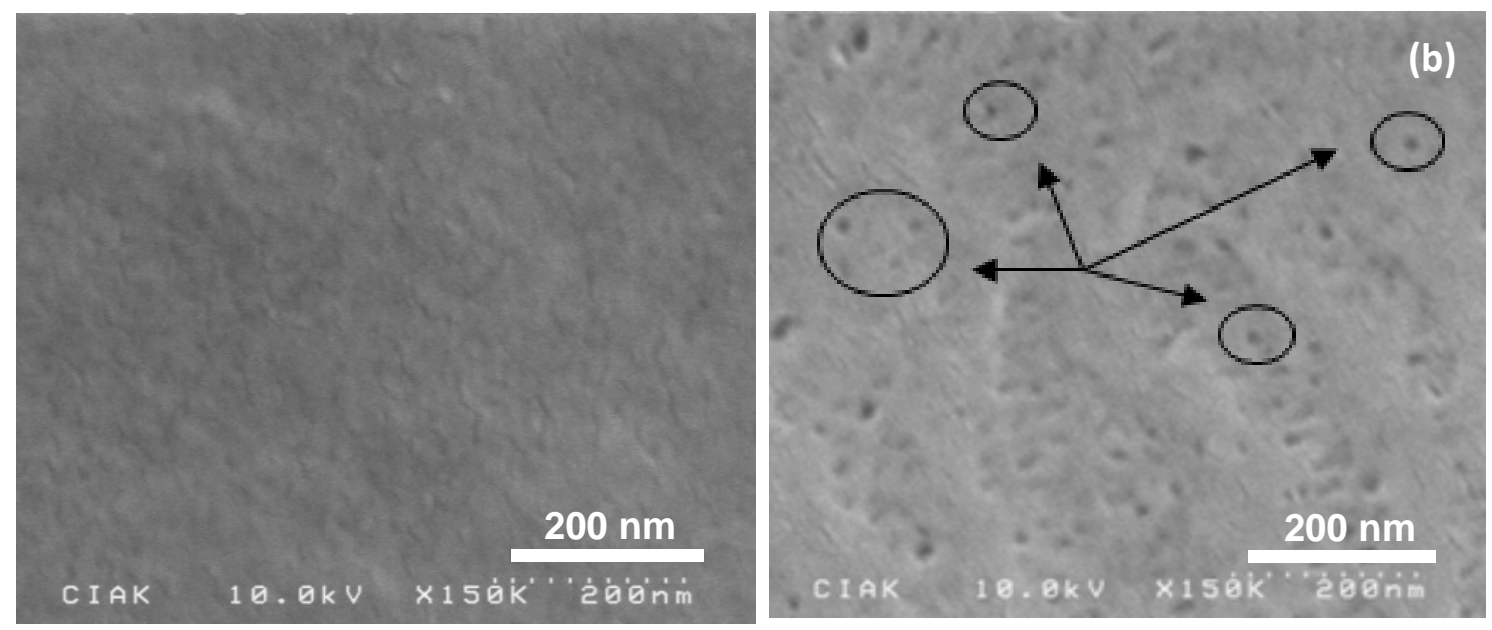

Figure 8 SEM surface images of (a) Psf (base) and (b) 0.1 wt\% Pdop-MWNT/Psf membranes
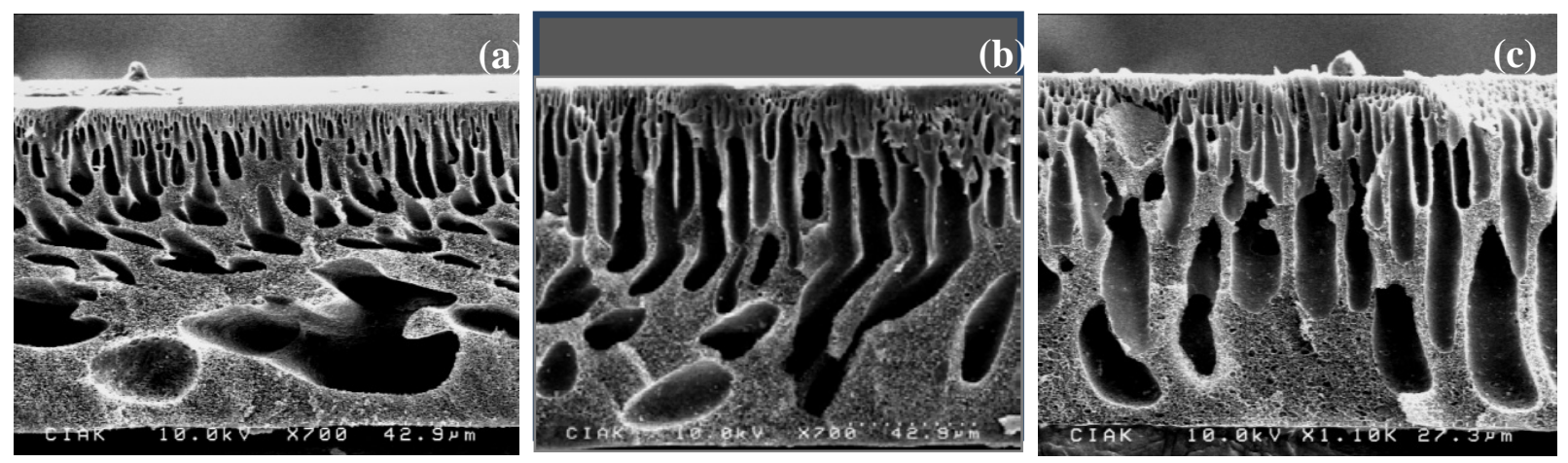

Figure 9 SEM images of the cross section of the (a) base membrane (b) $0.1 \mathrm{wt} \%$ and (c) 0.5 wt\% Pdop-MWNT/Psf membranes 


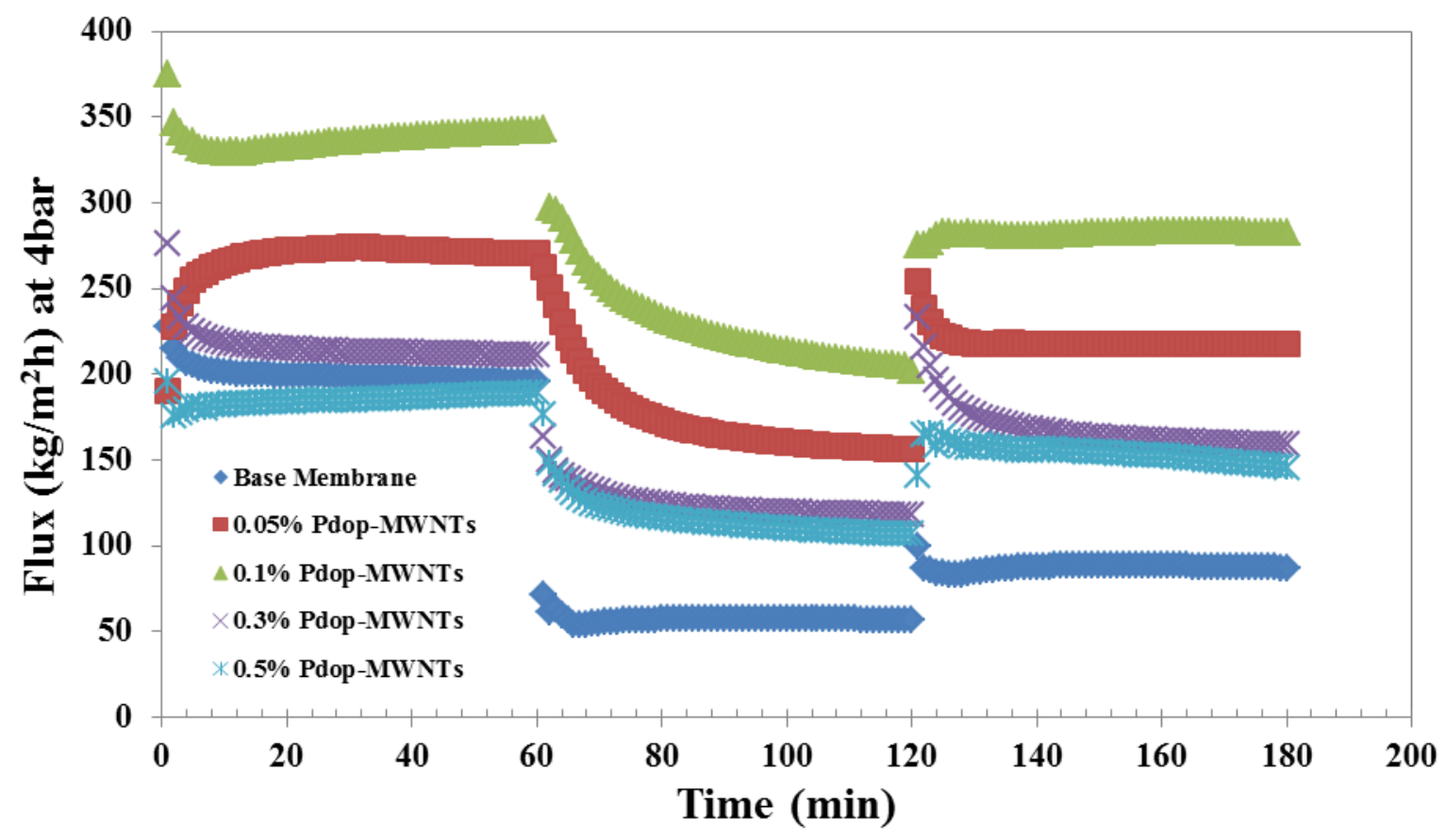

Figure 10 Flux behavior of the different membranes at: 60 minutes of DI water filtration (curves at $\mathrm{t}=0$ to $60 \mathrm{~min}$ ), 60 minutes of BSA solution $(150 \mathrm{ppm}$ ) filtration (curves at $\mathrm{t}=60$ to $120 \mathrm{~min}$ ), and 60 minutes of DI water filtration after backwash process for 20 minutes (curves at $\mathrm{t}=120$ to $180 \mathrm{~min})$. 